\title{
ANÁLISE INTEGRADA DOS PROCESSOS DE DESSULFURAÇÃO PARA OTIMIZAÇÃO DE ROTAS NA PRODUÇÃO DE AÇO*
}

\section{Resumo}

\author{
Lucas Teixeira Costa \\ Bernardo Braga Margins ${ }^{1}$ \\ Carlos Eduardo Passagli Barral ${ }^{1}$ \\ Roberto Parreiras Tavares ${ }^{2}$ \\ Nestor Cezar Heck
}

Por meio de modelamento matemático dos processos de dessulfuração de gusa e aço, em processo KR e forno panela, respectivamente, o presente trabalho tem como objetivo estabelecer rotas de produção de aços proporcionando aumento da produtividade e redução de custos. Foram avaliadas as seguintes rotas de produção: dessulfuração apenas no aço, dessulfuração apenas no gusa e dessulfuração no gusa e no aço, quais os produtos podem ser obtidos em cada rota de tratamento e quais as condições para a fabricação de aço baixo enxofre, com teores abaixo de 20ppm. Além disso, desenvolveu-se um balanço de enxofre para o LD e um estudo dos fatores que mais impactam a reversão ou a dessulfuração nessa etapa da fabricação do aço. Ao final, foram determinadas faixas de trabalho que permitam ganhos integrados dos três processos e um modelo global de enxofre capaz de prever bons resultados para diferentes plantas e contingências operacionais de diferentes usinas.

Palavras-chave: Dessulfuração; Modelo matemático; KR; LD; Forno panela.

\section{EVALUATION OF INTEGRATED DESULPHURIZATION PROCESSES THROUGH CFD FOR OPTIMIZATION IN STEEL PRODUCTION}

\section{Abstract}

Through the mathematical modeling of desulfurization processes in pig iron and steel, this paper is focused in establish routes for steel production in integrated steel framework regarding productivity and cost reduction. So on, the following production shifts were evaluated: only steel desulfurization, only pig iron desulphurization and desulphurization on both steel and pig iron. The treatment conditions and route to obtain steel sulfur at levels below $20 \mathrm{ppm}$ were also defined. In addition, it was developed a sulphur balance for the BOF process to study the parameters that can promote or not the desulphurization in this reactor. Finally, the way these three treatment stations are used (KR, BOF and Ladle Furnace) makes a integrated model for sulphur evaluation in steel chain production, which can be applied to different plants with different operating processes and is suitable to provide good results.

Keywords: Desulphurization; CFD; KR; BOF; Ladle furnace.

Engenheiro Metalurgista, Mestre, Doutorando, PPGEM, UFMG, Belo Horizonte, Minas Gerais, Brasil.

2 Engenheiro Metalurgista, PhD, Professor Associado, Departamento de Engenharia Metalúrgica e de Materiais, UFMG, Belo Horizonte, Minas Gerais, Brasil.

3 Engenheiro Metalurgista, PhD, Professor Associado, Departamento de Metalurgia, UFRGS, Porto Alegre, Rio Grande do Sul, Brasil. 


\section{INTRODUÇÃO}

O enxofre está contido nas matérias-primas da fabricação do aço e, portanto, sua presença no fluxo de produção siderúrgica é inevitável. Os efeitos do enxofre nas propriedades do aço são bastante conhecidos. Após a solidificação do aço, o enxofre é encontrado na forma de inclusões de sulfeto. Tais inclusões afetam as propriedades como ductilidade, tenacidade e resistência à fadiga. Atualmente, a produção de aços de alta qualidade lida com a remoção do enxofre no gusa e no aço.

Conforme apresentado na figura 1, o processamento do metal líquido envolve várias etapas desde o alto-forno até o lingotamento.

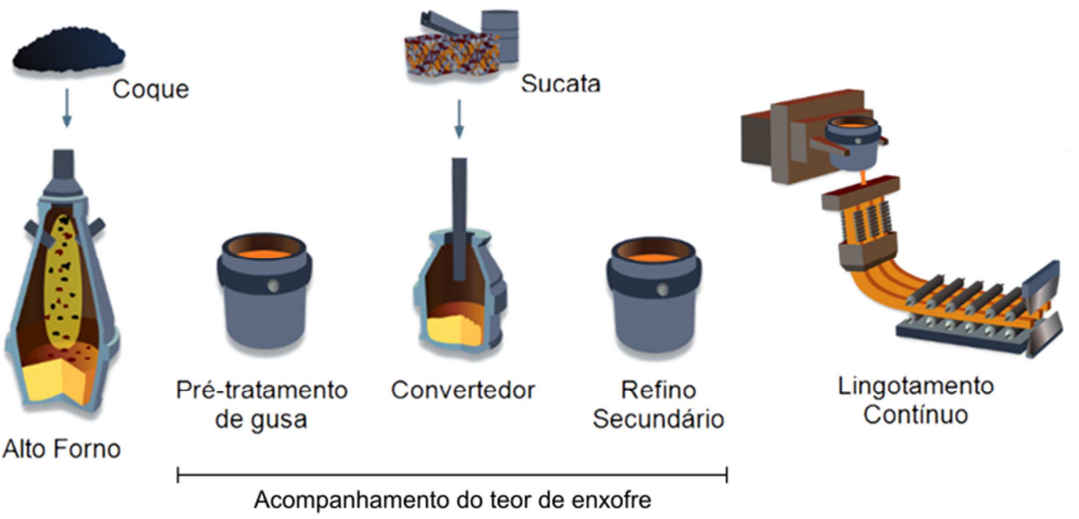

Figura 1 - Fluxograma adaptado do processo de fabricação do aço [1]

Em geral, a remoção do enxofre é realizada de forma a alcançar o melhor resultado em cada etapa, sem considerar que isso pode invalidar ganhos alcançados em etapas anteriores implicando em aumento considerável de custos de produção. Contudo, ainda que em menor quantidade, têm aparecido trabalhos explorando o uso estratégico de etapas isoladas [2-3]. A figura 2 mostra o acompanhamento industrial de três rotas para a produção de diferentes aços.

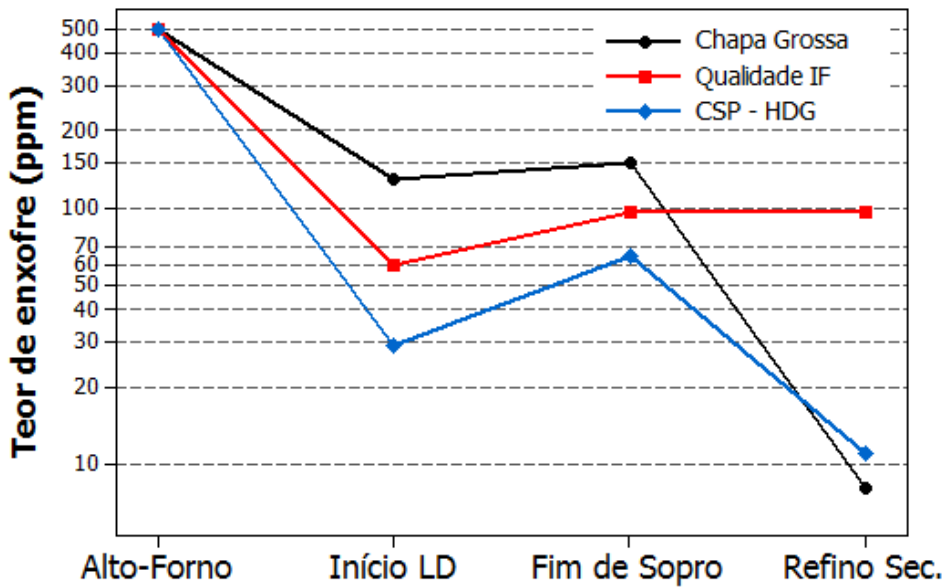

Figura 2 - Esquema adaptado do acompanhamento industrial do enxofre na produção do aço [4].

Na produção do aço IF, realiza-se a dessulfuração de gusa até 60ppm e ocorre uma reversão de enxofre no LD para 100ppm, teor final visado para essa qualidade. Nesse caso, o teor de enxofre visado é alcançado sem a necessidade de dessulfuração no aço. Nos aços para chapas grossas e HDG, Hot Dipped Galvanized, são adotadas estratégias diferentes em relação aos tratamentos de 
dessulfuração de gusa e aço que devem ser justificadas em função de razões específicas de cada usina.

O campo de estudo do presente trabalho é realizar a previsão do teor de enxofre ao longo das etapas envolvidas na produção do aço por meio de modelos matemáticos previamente validados. Uma curva semelhante à anteriormente citada será construída com a vantagem de que parâmetros podem ser avaliados com boa margem de acerto antes ou mesmo durante o processamento do aço.

A evolução dos teores de enxofre nos processos de dessulfuração de gusa e aço é calculada por meio de modelo fluidodinâmico computacional (CFD), e no LD foi criado um balanço de enxofre. Os referidos modelos foram validados com dados industriais disponíveis na literatura [5-8].

\section{MATERIAIS E MÉTODOS}

Considerou-se, no presente trabalho, que o reator LD precisa ser investigado por se tratar de uma etapa pouco mencionada na literatura quanto ao acompanhamento do enxofre ao longo da produção do aço. Assim, o acompanhamento global será realizado da seguinte forma: o modelo matemático $\mathrm{KR}$ dará o enxofre final como condição de entrada no LD, o balanço de massa no LD dará o enxofre final ao fim de sopro como entrada para o modelo de dessulfuração do aço em forno panela, que por sua vez dirá qual o teor final de enxofre é possível obter. Os três processos de tratamento abordados: dessulfuração de gusa, convertedor LD e refino secundário, dependem um do outro embora desacoplados. Suas considerações são apresentados nessa ordem nos tópicos a seguir.

\subsection{Pré Tratamento de Gusa}

Quando ocorre o tratamento de dessulfuração de gusa, a escória é enriquecida conforme a extensão da dessulfuração realizada. Para um tratamento de gusa em que houve remoção de enxofre de 400 para 20ppm, o teor de enxofre na escória é de 1,6\%. Na raspagem de escória após tratamento de gusa, parte considerável dessa escória rica em enxofre é carreada para o LD. A figura 3 apresenta resumidamente os valores envolvidos na dessulfuração do gusa e o modelo do processo KR.

\begin{tabular}{cc}
\hline Sinicial Gusa $(\mathrm{ppm})$ & $500-350$ \\
Sfinal Gusa $(\mathrm{ppm})$ & $20-120$ \\
S escória AF $(\%)^{[9]}$ & $0,5-0,95$ \\
Tempo máximo de tratamento & 20 minutos \\
Adições para dessulfuração $(\mathrm{kg} / \mathrm{t})$ & 11 \\
\hline
\end{tabular}

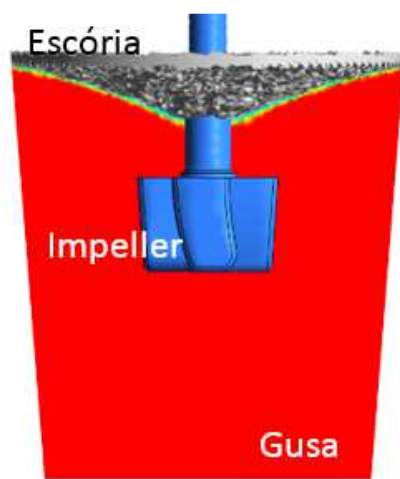

Figura 3 - Representação esquemática e parâmetros operacionais do reator KR

Este primeiro modelo informa para o LD o teor de enxofre no gusa e na escória carreada. Permite também variar o tempo de tratamento para projeções de alterações no custo e produtividade global. 


\subsection{Balanço de Enxofre no LD}

Além do teor de enxofre remanescente no gusa tratado e da escória carreada, o enxofre também é adicionado no LD por meio de fundentes (Cal calcítica e Cal dolomítica) e sucata. Após terem sido consideradas todas as fontes de enxofre envolvidas no processo LD, uma rotina que considera a concentração de enxofre no metal, na escória e a partição de enxofre no equilíbrio $\left(L_{s}\right)$ determinada por FactSage, foi desenvolvida para determinar o sentido de transferência de massa. $A$ equação 1 representa a distribuição de enxofre entre as fases que é valida na condição de equilíbrio de transferência de enxofre no LD, em que havendo igualdade na expressão obtém-se o teor de enxofre de fim de sopro. A figura 4 apresenta 0 fluxograma da rotina de programação utilizada para calcular a dessulfuração ou reversão de enxofre.

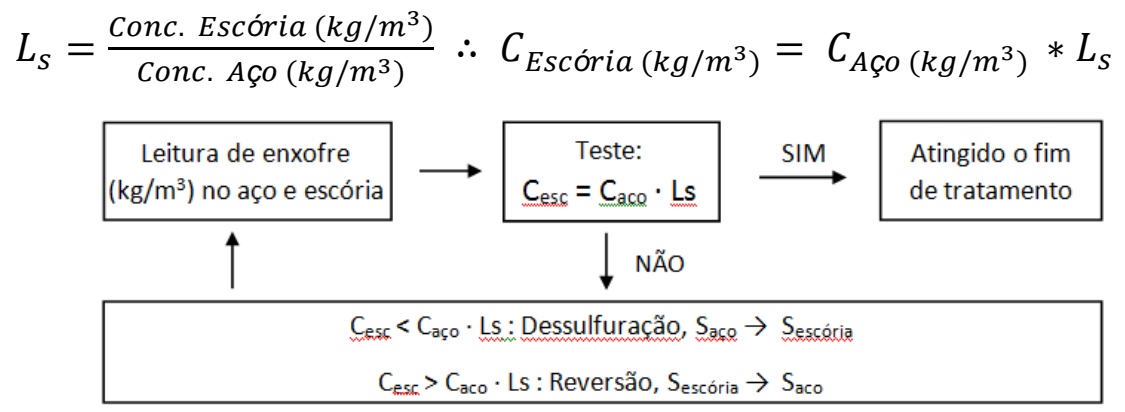

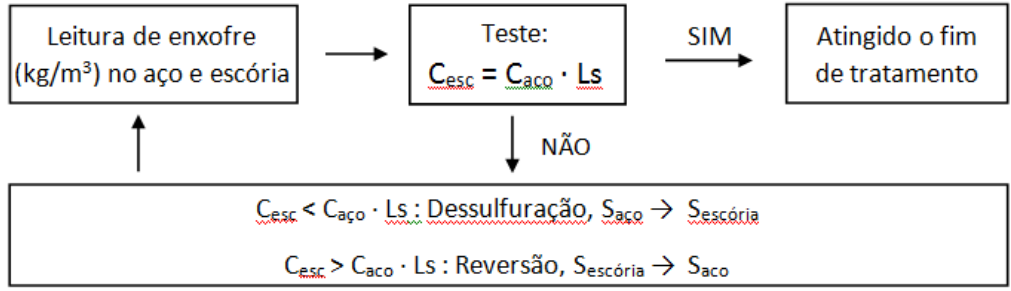

Figura 4. Fluxograma esquemático da rotina de previsão do enxofre no fim de sopro

Apesar do ambiente oxidado e de pouca eficiência na remoção de enxofre, essa possibilidade foi avaliada utilizando $L_{s}=4,5$; valor calculado pelo FactSage.

Um estudo da sensibilidade do teor de enxofre no fim de sopro em função das variáreis do processo foi realizado por meio de planejamento fatorial completo, $2^{5}$, utilizando os níveis apresentados na tabela 1.

Tabela 1 - Níveis inferiores e superiores para teste de sensibilidade no LD

\begin{tabular}{ccccc} 
Escória passante (kg) & S Gusa (\%) & S Cal (\%) & S Sucata (\%) & Fração Sucata \\
$750-1500$ & $0,002-0,005$ & $0,006-0,010$ & $0,005-0,015$ & $0,10-0,15$ \\
\hline
\end{tabular}

Após o conhecimento do impacto no teor de enxofre no fim de sopro pelas matérias primas foram propostas formas de utilização racional do LD para obtenção de ganho global.

\subsection{Refino Secundário do Aço}

A dessulfuração do aço foi simulada por meio de um modelo de fluidodinâmica computacional validado com dados industriais de forno panela. $O$ modelo foi desenvolvido sob a plataforma do programa ANSYS CFX 14.5 e trata-se de uma abordagem trifásica (aço, escória e argônio) para resolver as equações de quantidade de movimento e transferência de massa no processo de dessulfuração do aço em forno panela.

Os tratamentos de dessulfuração em refino secundário foram simulados por um tempo total de 60 minutos, porém, considerou-se para a avaliação das rotas 0 tratamento feito em 25 minutos. Para enxofre visado abaixo de 20ppm, os dados 
simulados até 60 minutos são utilizados pela necessidade de tempo maior de tratamento. Uma quantidade típica de escória sintética de $10 \mathrm{~kg} / \mathrm{t}$ foi adicionada, perfazendo um total de $18(\mathrm{~kg} / \mathrm{t}$ aço) considerando-se a escória passante [9] vinda do LD. A composição química utilizada nas simulações foi: 45,6\% $\mathrm{CaO}, 12,1 \% \mathrm{MgO}$, $5,0 \% \mathrm{SiO}_{2}, 25,5 \% \mathrm{Al}_{2} \mathrm{O}_{3}$, e 7,5\% $\mathrm{CaF}_{2}$; que apresenta $\mathrm{L}_{\mathrm{s}} \sim 128,4$ [10-11] e conferidos no FactSage. Essas condições operacionais do forno panela foram aplicadas aos resultados obtidos no balanço de enxofre de LD.

Embora exista a possibilidade de alterar a composição química da escória e consequentemente aumentar sua capacidade de enxofre, optou-se por realizar a dessulfuração do aço no processo de refino secundário sob as mesmas condições para os diferentes teores de enxofre provenientes do LD. A figura 5 apresenta um esquema do modelo construído.
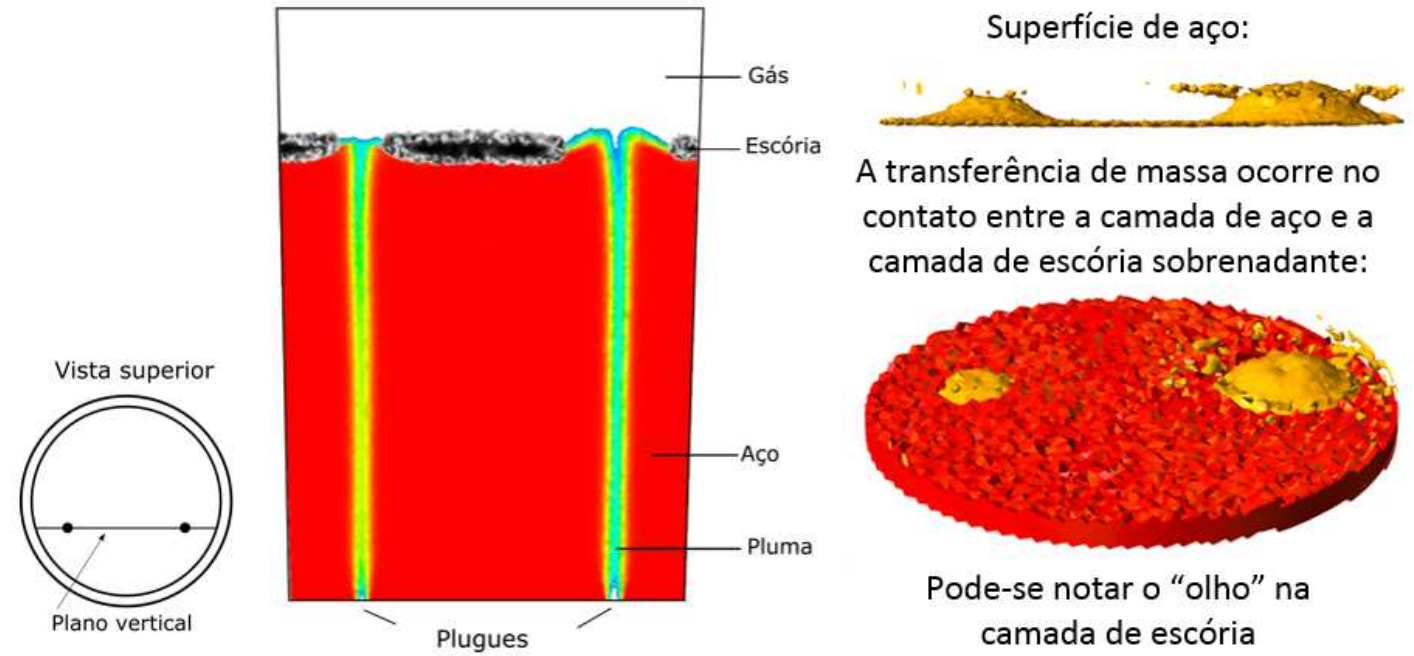

Figura 5 - Esquema do modelo de dessulfuração de aço em panela.

\section{RESULTADOS E DISCUSSÃO}

Primeiramente, foram investigados os efeitos das matérias primas carregadas no LD visando controle do teor de enxofre no final de sopro. Em seguida, realizaram-se simulações de possibilidades operacionais na indústria com vistas à obtenção do melhor proveito do processo LD nas seguintes condições:

- Obtenção do enxofre visado dessulfurando apenas o aço;

- Obtenção do enxofre visado dessulfurando apenas o gusa;

- Obtenção do enxofre visado dessulfurando o gusa e o aço.

Ao final das simulações, realiza-se uma análise e proposição da melhor alternativa de rota de fabricação para cada faixa de teor de enxofre visado no produto final.

\subsection{Estudo da Sensibilidade dos Fatores Operacionais do LD}

O balanço de massa de enxofre no LD levou em consideração os seguintes fatores: enxofre inicial no gusa, cal e sucata, além de fração de sucata e quantidade de escória passante do tratamento de gusa na estação de dessulfuração. Os níveis de cada um desses fatores estão expostos na figura 6, que apresenta o impacto no teor final de enxofre no LD, em ppm, e resultados da evolução de enxofre no LD mediante a mudança dos parâmetros. 


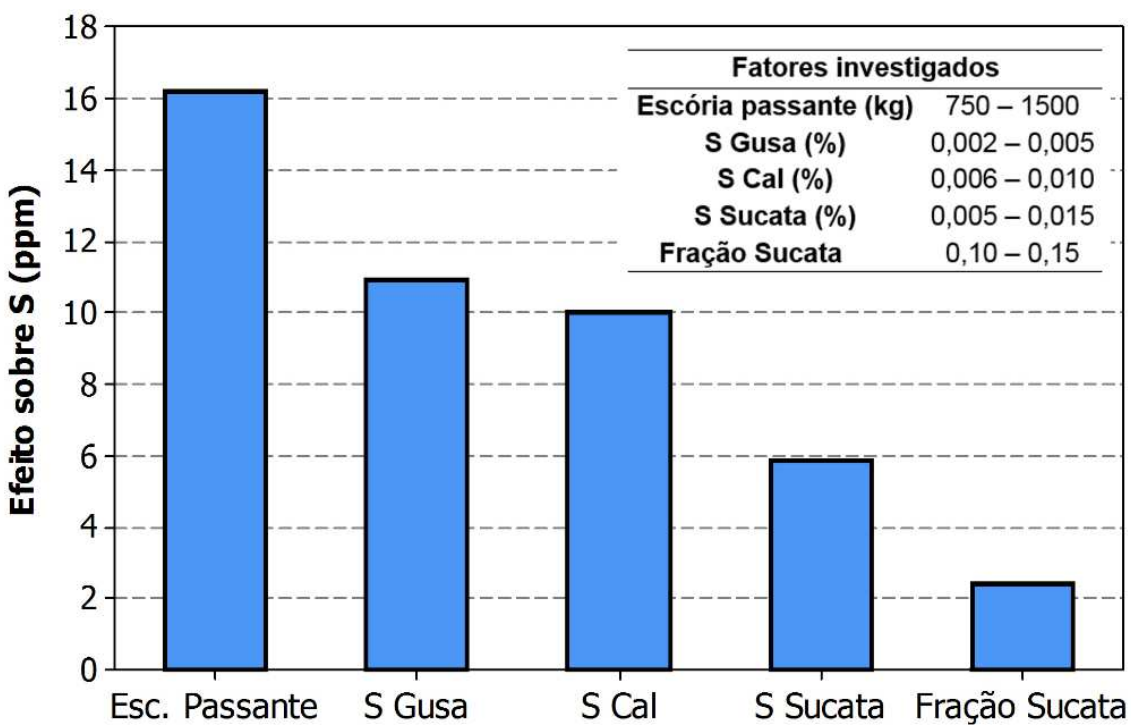

Figura 6- Influência dos parâmetros de processo no "pick-up" de enxofre no LD.

O gráfico de barras dos efeitos mostra que o peso de escória passante apresenta maior influência no teor de enxofre no fim de sopro, 16ppm. Essa alteração é entendida da seguinte forma: o aumento gradual do peso de escória carregada no LD pode causar um aumento de até $16 \mathrm{ppm}$ no teor final do aço, partindo-se do menor valor de carregamento $(750 \mathrm{~kg})$ ao maior valor $(1500 \mathrm{~kg})$. Os demais parâmetros estão discriminados na referida figura por ordem decrescente de influência, e devem ser interpretados da mesma forma, a resposta em ppm de enxofre em função das alterações possíveis.

\subsection{Dessulfuração apenas no Aço}

A figura 7 apresenta o resultado de uma simulação em que a dessulfuração ocorre somente no refino secundário do aço, no forno panela, partindo-se de teores de enxofre no gusa de 400 a 200ppm. Pode-se ver que o carregamento do LD com sucata $(S=0,02 \%)$ gera diluição do teor de enxofre para as duas primeiras situações simuladas, 400 e $300 \mathrm{ppm}$, a isso se deve a queda antes do início de sopro. Devido aos elevados teores contidos na carga metálica, a etapa de refino primário contribui com uma redução no teor de enxofre de 30 a $40 \%$, o que não se repete em condições de gusa entrando no LD com teores iniciais mais baixos.

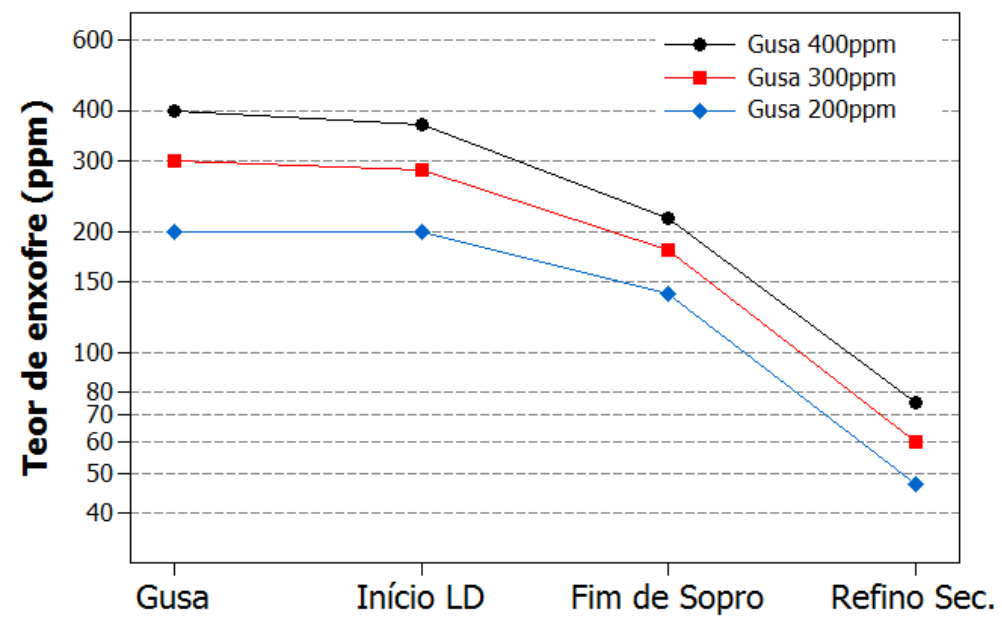

Figura 7 - Evolução do teor de enxofre no aço sem pré-tratamento de gusa 
A dessulfuração no refino secundário indica que são atingidos teores de enxofre na panela de 45 a 80ppm. Essa rota de produção é bastante interessante para os casos em que o metal líquido já passa pelo forno panela para ajustes finos de composição química e temperatura, além de promoção da limpidez do aço. Além disso, o balanço térmico LD é favorecido, pois o gusa vindo direto do alto-forno chega com temperatura mais elevada do que se houvesse sido dessulfurado. Isso permite aumentar a proporção de sucata na carga metálica. Pode-se afirmar que é possível produzir, com garantia de acerto, mesmo considerando as variações de teores de enxofre do gusa até $400 \mathrm{ppm}$, aços com requisitos de teores de enxofre acima de 80ppm.

\subsection{Dessulfuração apenas no Gusa}

A figura 8 apresenta o resultado das simulações realizadas para situações em que se carrega no LD gusa previamente dessulfurado a teores de enxofre variando de 20 a 80ppm e não se realiza tratamento de dessulfuração no refino secundário. Podese afirmar que é possível produzir, com garantia de acerto, aços com requisitos de teores de enxofre acima de 100ppm. Além disso, conforme a figura, faz pouca diferença a extensão final de tratamento do gusa porque quanto menor o enxofre carregado no LD maior a reversão de enxofre. Novamente, isso se deve a concentração desse elemento na escória que é muito maior que o contido no metal e essa diferença aumenta significativamente à medida que o teor de enxofre no gusa carregado diminui.

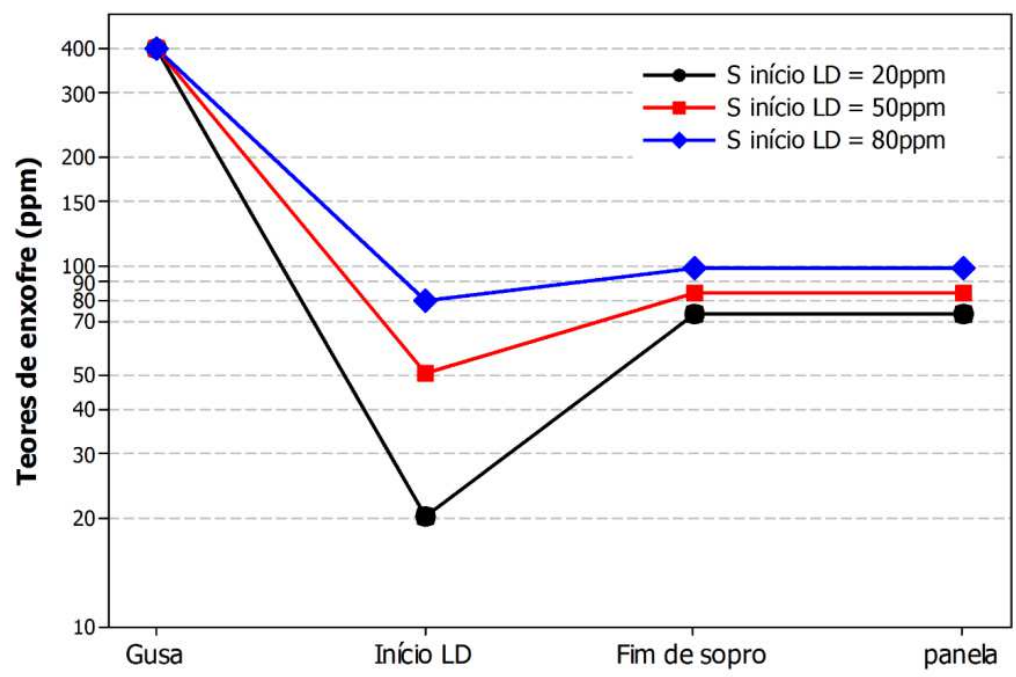

Figura 8 - Produção de aços dessulfurando apenas no gusa

\subsection{Dessulfuração Realizada no Gusa e no Aço}

A figura 9 apresenta a evolução dos teores de enxofre no gusa e no aço para diferentes níveis de dessulfuração realizada no gusa e seu impacto posterior. 


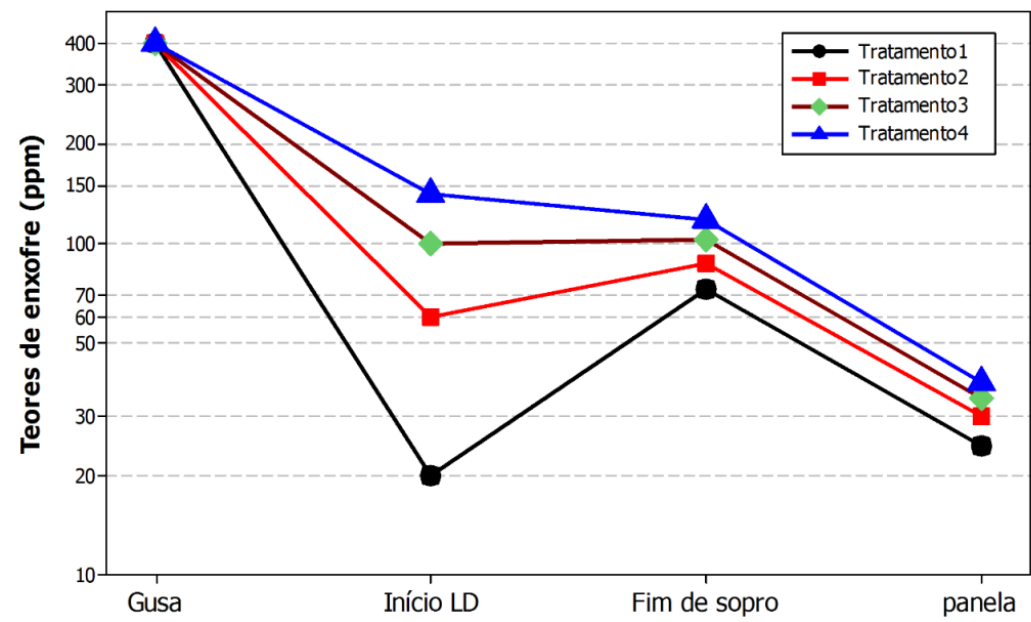

Figura 9 - Dessulfuração no gusa e no aço

Pode-se observar que o teor de enxofre no gusa de 100ppm é o valor limite para que não ocorra reversão de enxofre para o metal. Nesse teor, todo o esforço dispendido na etapa de dessulfuração de gusa é mantido no refino primário do aço. Abaixo desse teor, começa a ocorrer perda de eficiência devido à reversão de enxofre no LD. Portanto, para a produção de aço com requisitos de enxofre final no aço de 40 a 80ppm, com otimização dos custos de produção, deve-se carregar no LD, gusa líquido com teores de enxofre variando na faixa de 100 a 140ppm.

\subsection{Produção de Aços com Teor de Enxofre Inferior a 20 ppm}

Para se obter enxofre final abaixo de 20ppm são destacados três pontos, a utilização de matérias primas mais puras no LD, que impactaria num custo elevado; processo de raspagem otimizado, evitando assim reversão de enxofre; e por fim o aumento da quantidade de escória utilizada no forno panela e o tempo de operação. Este último caminho foi o escolhido no presente trabalho.

A tabela 2 apresenta os teores de enxofre estimados, via simulação matemática, em função do tempo de tratamento no forno panela e do teor de enxofre inicial utilizando peso de escória de $20 \mathrm{~kg} / \mathrm{t}$.

Tabela 2 - Possíveis valores de enxofre final para tempo de tratamento e enxofre fim de sopro.

\begin{tabular}{cccccc}
\hline Tempo & \multicolumn{5}{c}{ Enxofre inicial no Forno Panela $(\mathrm{ppm})$} \\
$(\mathrm{min})$ & $\mathbf{4 0}$ & $\mathbf{6 0}$ & $\mathbf{8 0}$ & $\mathbf{1 0 0}$ & $\mathbf{1 2 0}$ \\
\hline $\mathbf{3 0}$ & 9 & 14 & 19 & 23 & 28 \\
$\mathbf{4 5}$ & 6 & 10 & 13 & 16 & 19 \\
$\mathbf{6 0}$ & 5 & 7 & 10 & 12 & 15 \\
\hline
\end{tabular}

Com a possibilidade de alcançar valores de enxofre abaixo de 20ppm, conforme a tabela acima, a figura 10 apresenta a evolução integrada do teor de enxofre na fabricação do aço para dois casos distintos. Trecho I - dessulfuração de gusa no processo KR por meio de modelamento matemático validado com dados industriais; trecho II - evolução do teor de enxofre no LD por meio de balanço de massa validado com dados industriais; trecho III - evolução do teor de enxofre no refino secundário de aço por meio de modelamento matemático validado com dados industriais. 


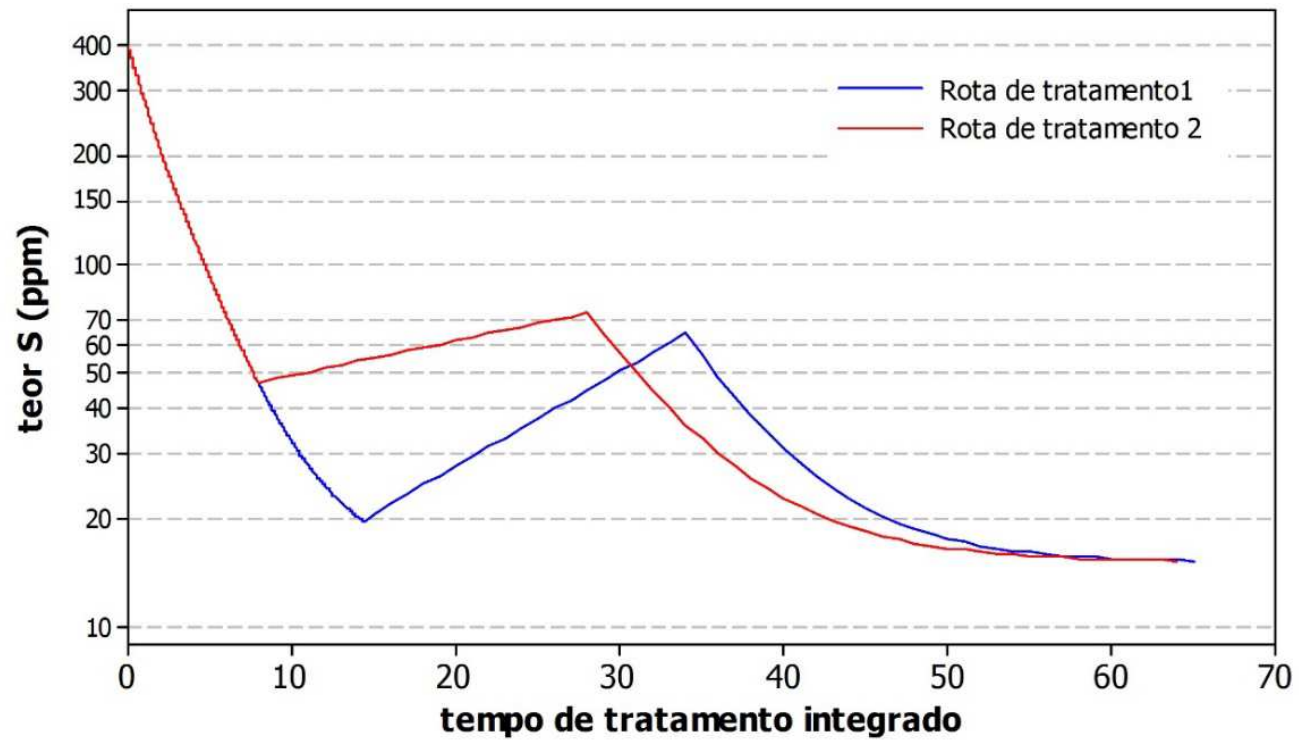

Figura 10 - Evolução do teor de enxofre ao longo do processamento do aço.

Chama a atenção o fato de que o tempo demandado para a dessulfuração de gusa aumenta de 8 para 14 minutos, para levar o enxofre de 50 ppm para 20ppm. Considera-se, portanto, que parar a dessulfuração do gusa em 50ppm gera ganho de 8 minutos. Há porém um desconto de 2 a 3 minutos no forno panela, tempo comparativo gasto para obter mesmo teor final da rota concorrente, fazendo assim, um ganho de 3 a 4 minutos, ou seja cerca de 7\%. Logo, é recomendável visar na dessulfuração de gusa, teores de enxofre inferiores a 50 ppm, porém mais próximo desse valor. Tal fato está em perfeita concordância com os teores de enxofre de fim de tratamento de dessulfuração de gusa apresentados na figura 2.

Todavia, a extensão da dessulfuração de aço, para a produção de aços chapas grossas, apresentada pelo referido autor, demanda muito tempo de forno panela, possivelmente pela exigência de elevado grau de limpidez no aço. Mas isso implica em aumento significativo dos custos de produção. A tabela 3 apresenta esquemas de operação definidos a partir do uso dos modelos de forma integrada, objetivado no presente trabalho.

Tabela 3 - Rotas propostas para a produção aços com diferentes níveis de enxofre em ppm

\begin{tabular}{ccccc}
\hline $\begin{array}{c}\text { Enxofre } \\
\text { visado no } \\
\text { aço final }\end{array}$ & $\begin{array}{c}\text { Dessulfuração } \\
\text { de Gusa }\end{array}$ & $\begin{array}{c}\text { S entrada no } \\
\text { LD }\end{array}$ & S fim de sopro & $\begin{array}{c}\text { Dessulfuração } \\
\text { de Aço }\end{array}$ \\
\hline$S>80$ & NÃO & 400 a 200 & $\begin{array}{c}\text { Dessulfuração } \\
210 \text { a } 140\end{array}$ & SIM \\
$30<S<80$ & SIM & 100 a 140 & $\begin{array}{c}\text { S é mantido } \\
100 \text { a } 120\end{array}$ & SIM \\
$S<20$ & SIM & 50 a 20 & $\begin{array}{c}\text { Reversão } \\
75 \text { a } 65\end{array}$ & SIM* $^{*}$ \\
\hline
\end{tabular}

*escória de topo $20 \mathrm{~kg} / \mathrm{t}$

\section{CONCLUSÃO}

A utilização combinada dos três modelos matemáticos (KR, LD e Forno Panela) mostrou-se capaz de prever diferentes possibilidades de tratamento de 
dessulfuração.

A partir da aplicação dessa ferramenta e do enxofre final visado é possível encontrar rotas de tratamento que resultam em tempo de produtividade, vida útil de reator, tempo total de tratamento e portanto, impacto nos custos de produção.

O efeito do LD no teor de enxofre do aço foi investigado para diferentes teores de enxofre no gusa, antes do sopro, sempre tomando como referência o teor de enxofre visado no aço. Buscou-se atingir os requisitos de qualidade de forma mais racional para oferecer rotas de produção e opções economicamente viáveis para cada tratamento.

O modelo integrado proposto neste trabalho pode ser aplicado para estudo dos custos de produção pelo tipo de matéria prima utilizada, quantidade de sucata carregada no LD, quantidade de escória nos dois processos de dessulfuração. Além disso, apresenta possibilidade de ser aplicado em diferentes usinas e instalações industriais. Tem-se assim, uma ferramenta confiável para controle global de enxofre de uma aciaria.

\section{Agradecimentos}

CNPq pela bolsa de doutorado concedida, processo 140893/2012-1

FAPEMIG pelo apoio financeiro no projeto PPM-00118-13: Modelagens física e matemática do escoamento multifásico em reatores metalúrgicos.

\section{REFERÊNCIAS}

1 Worldsteel Association, Overview of the steelmaking process, Worldsteel.org, 2012

2 Bol'shakov VI, Shevchenko AF, Ye LD, Aleksandrov VA, Sen ST, Bashmakov AM, Trotsenko EA. Rational Ladle Treatment for Desulfurization of Hot Metal. Steel in Translation, 2009, Vol. 39, No. 4, pp.

3 Visser H, Boom R, Biglari M, Simulation of the Ca-treatment of Al-killed liquid steel. La Revue de Métallurgie - CIT - abril 2008, pp 172-180

4 Hüsken R, Cappel J, Estratégias de dessulfuração na fabricação de aço com oxigênio. MPT Edição Brasileira, p24, 2/2013

5 Costa LT, Simulação fluidodinâmica computacional para estudo do tratamento de dessulfuração do aço [dissertação de mestrado]. Belo Horizonte: UFMG; 2012.

6 Filipe BC, Redução do teor de fósforo dos aços em convertedores LD através de adição de briquete [dissertação de mestrado]. Belo Horizonte: UFMG; 2012.

7 Kirmse OJ. Estudo do comportamento metalúrgico do "reator kambara" através de modelagem física, dissertação de mestrado. Universidade Federal de Ouro Preto; 2006

8 Lemos LR, Silva CA, Silva IA, Mansur F, Seshadri V, Kirmse OJ. Aumento da eficiência de dessulfuração do gusa líquido em um reator kanbara. Tecnol. Metal. Mater. Miner., São Paulo, v. 8, n. 1, p. 31-36, jan.-mar. 2011

9 X. Yang, J. Jiao, R. Ding, C. Shi, H. Guo A Thermodynamic Model for Calculating Sulphur Distribution Ratio between $\mathrm{CaO}-\mathrm{SiO} 2-\mathrm{MgO}-\mathrm{Al} 2 \mathrm{O} 3$, Ironmaking Slags and Carbon Saturated Hot Metal Based on the Ion and Molecule Coexistence Theory. ISIJ International, Vol. 49 (2009), No. 12, pp. 1828-1837.

10 Mills K. Viscosities of molten slags. In: Slag Atlas. Düsseldorf, 1995. 2nd edition 2008

11 Gaye H, Lehmann J. Modelling and prediction of reactions involving metals, slags and fluxes, VII International Conference on Molten Slags Fluxes and Salts, The South African Institute of Mining and Mettalurgy, 2004. 